\title{
Diagnosis of the MJO Modulation of Tropical Cyclogenesis Using an Empirical Index
}

\author{
SUZANA J. CAMARGO \\ Lamont-Doherty Earth Observatory, The Earth Institute at Columbia University, \\ Palisades, New York \\ MATTHEW C. WHEELER \\ Centre for Australian Weather and Climate Research, Melbourne, Australia \\ ADAM H. SOBEL \\ Department of Applied Physics and Applied Mathematics, and Department of Earth \\ and Environmental Sciences, Columbia University, New York, New York
}

(Manuscript received 6 February 2009, in final form 28 April 2009)

\begin{abstract}
The modulation of tropical cyclone activity by the Madden-Julian oscillation (MJO) is explored using an empirical genesis potential (GP) index. Composite anomalies of the genesis index associated with the different MJO phases are consistent with the composite anomalies in TC genesis frequency that occur in the same phases, indicating that the index captures the changes in the environment that are at least in part responsible for the genesis frequency changes. Of the four environmental variables that enter the genesis potential index, the midlevel relative humidity makes the largest contribution to the MJO composite GP anomalies. The second largest contribution comes from the low-level absolute vorticity, and only very minor contributions come from the vertical wind shear and potential intensity.

When basin-integrated MJO composite anomalies of the GP index are regressed against basin-integrated composite anomalies of TC genesis frequency, the results differ quantitatively from those obtained from the analogous calculation performed on the annual climatologies in the two quantities. The GP index captures the MJO modulation of TC genesis to a lesser degree than the climatological annual cycle of genesis (to which it was originally tuned). This may be due to weaknesses of the reanalysis or indicative of the importance of precursor disturbances, not well captured in the GP index computed from weekly data, to the intraseasonal TC genesis frequency fluctuations.
\end{abstract}

\section{Introduction}

Tropical cyclone (TC) activity is influenced by a variety of modes of natural climate variability across a range of time scales (e.g., Camargo et al. 2009). On the intraseasonal time scale, the Madden-Julian oscillation (MJO) exerts a strong influence on TC activity in several basins. Globally, the MJO is the most prominent mode of intraseasonal variability, characterized by planetaryscale fluctuations of deep convection and atmospheric

Corresponding author address: Suzana J. Camargo, LamontDoherty Earth Observatory, Columbia University, Palisades, NY 10964-8000.

E-mail: suzana@1deo.columbia.edu circulation propagating eastward along the equator with a period in the range of about 30 to 80 days (Madden and Julian 1972, 1994; Zhang 2005). Its cycle in convection usually starts with a period of enhanced convection in the equatorial Indian Ocean, which then propagates eastward across the Maritime Continent into the Pacific. After reaching the Pacific, MJO disturbances continue through the Western Hemisphere but have weaker signals in convection there. The latitudinal axis of the MJO's convective signal shifts north and south with the seasons, maximizing in the summer hemisphere as does TC activity. Globally, the strongest MJO events usually occur in boreal winter (Wang and Rui 1990).

The modulation of TCs by the MJO was first noted for the case of the western North Pacific and Indian Oceans 
(a) Phases 2+3 - JFM

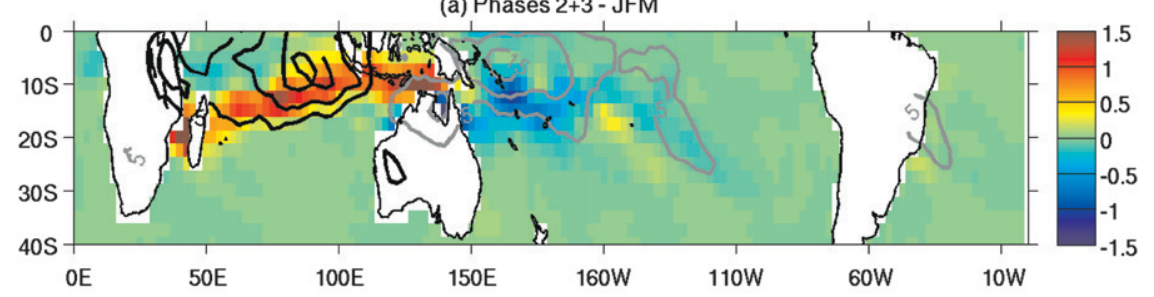

(b) Phases 4+5 - JFM

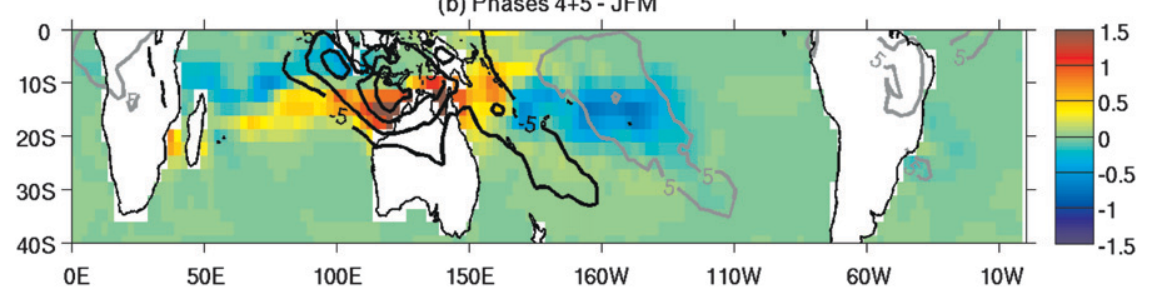

(c) Phases $6+7-$ JFM

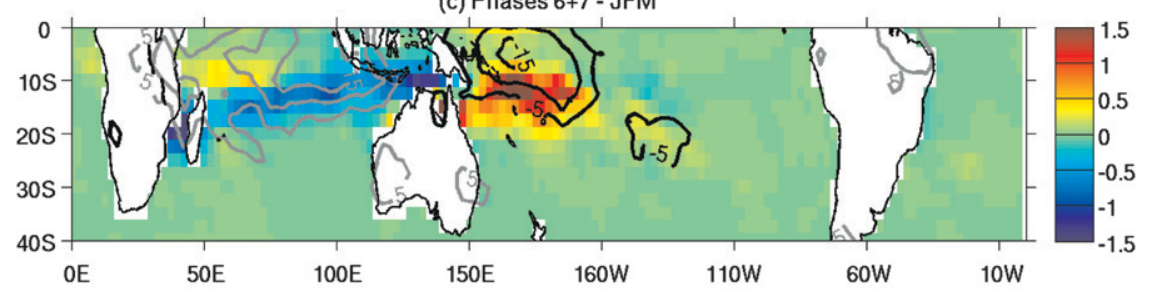

(d) Phases 8+1 - JFM

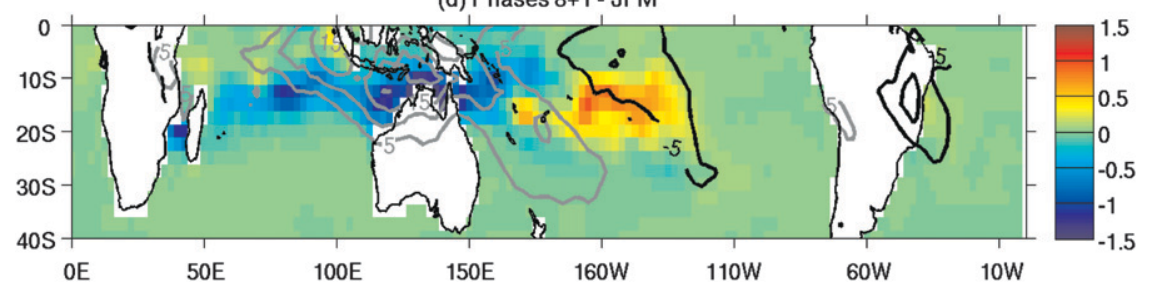

FIG. 1. GP (colors) and OLR (contours) anomaly composites for JFM in different MJO phases. The OLR positive (negative) anomalies are shown in gray (black) and the contours are plotted for every $5 \mathrm{~W} \mathrm{~m}^{-2}$ for MJO phases (a) 2 and 3 (Indian Ocean), (b) 4 and 5 (Maritime Continent), (c) 6 and 7 (western Pacific), and (d) 8 and 1 (Western Hemisphere and Africa). The GP was calculated using the NCEP-NCAR reanalysis data for the period 1982-2007.

basins by Nakazawa (1988) and Liebmann et al. (1994). These studies demonstrated an approximate match between the enhanced convective phase of the MJO and the increased activity of TCs. A similar modulation has also been found in the eastern North Pacific (Molinari et al. 1997; Maloney and Hartmann 2001), the Gulf of Mexico (Maloney and Hartmann 2000b), the South Indian Ocean (Bessafi and Wheeler 2006; Ho et al. 2006), and the Australian region (Hall et al. 2001).

Although it is now very well known that modulation of TC activity by the MJO occurs, it is not clear exactly what the mechanism of the modulation is. TC genesis is thought to be influenced by a number of different large-scale environmental fields, such as low-level vorticity and vertical wind shear, and previous studies have shown some consistency between the MJO's modulation of these fields and its modulation of TCs (e.g., Maloney and Hartmann 2000a; Hall et al. 2001; Bessafi and Wheeler 2006). However, no quantitative estimate of the relative impacts of the different large-scale fields of the MJO for the observed TC modulation has been made. Recently, Aiyyer and Molinari (2008) used idealized numerical simulations and a case study to examine the relationship of the MJO with tropical cyclogenesis in the Gulf of Mexico and eastern North Pacific.

In this paper we analyze the modulation of TCs by the MJO using a previously defined genesis potential (GP) index. The index is an empirically determined function of four environmental factors believed to be related to TC genesis: low-level absolute vorticity, vertical wind shear, midlevel relative humidity, and potential intensity. It was designed to be able to replicate the climatological annual 
(a) Phases 2+3 - ASO

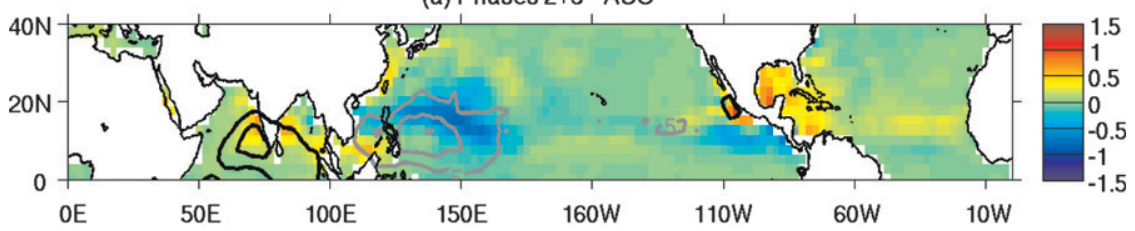

(b) Phases 4+5 - ASO

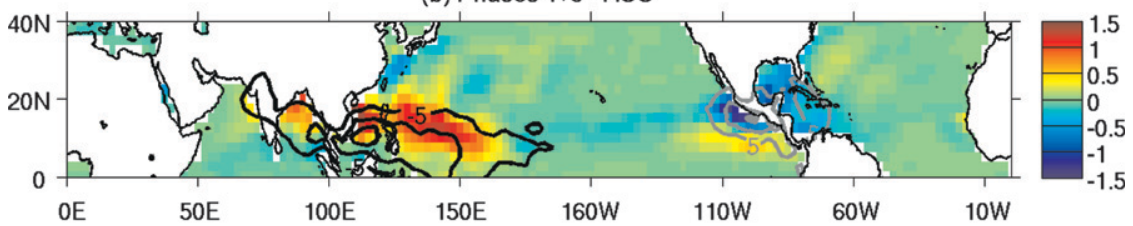

(c) Phases 6+7 - ASO

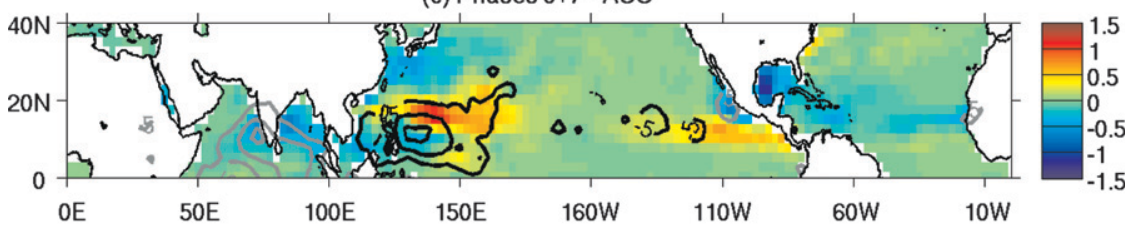

(d) Phases 8+1 - ASO

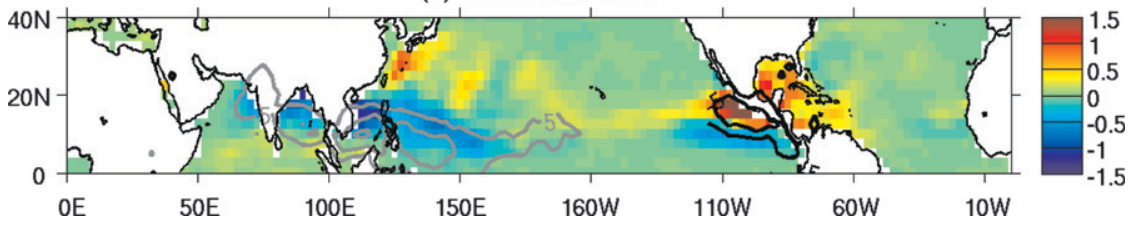

FIG. 2. As in Fig. 1, but for ASO.

cycle of TC genesis in each hemisphere and its spatial distribution. No aspect of variability about the climatology (e.g., intraseasonal variability) was used in the derivation of the index. We first examine the extent to which the fluctuations in the genesis index associated with the MJO coincide in space and time with observed MJO fluctuations in TC genesis frequency of the same sign. As part of this we assess the extent to which the MJO signal in the index is influenced by the presence of the TCs themselves. We do this by repeating all calculations of the genesis index with modified datasets from which the TCs have been removed, ensuring that any remaining MJO signals are truly representative of only of the largescale environment for TC formation, rather than the presence or absence of TCs. Finding that the qualitative match of the MJO-associated variations in the index (with and without TCs included) with the TC genesis frequency is relatively good, we then analyze the relative importance to the MJO signal of each variable that enters the index. Finally, we test the extent to which the genesis potential index can quantitatively reproduce the magnitude of the observed MJO modulation of TC genesis frequency. In addition to improved understanding, the results are potentially useful for future developmental work on intraseasonal TC genesis frequency prediction (e.g., Leroy and Wheeler 2008) because they imply that the index may be usefully applied to the extended-range output of coarse-resolution numerical weather prediction models.

Section 2 describes the datasets used in this study. In section 3 we present the definition of the genesis index and describe the construction of the MJO composites. The resulting composites are shown and discussed in section 4 . We explore the contribution of the TCs themselves to the MJO signal in the index in section 5. The relative importance of individual environmental factors is assessed in section 6. Quantification of the relationship between MJO fluctuations in the environment-represented by the genesis index-and TC genesis itself appears in section 7; conclusions are given in section 8 .

\section{Datasets}

We used the weekly sea surface temperature (SST) dataset by Reynolds et al. (2002). This weekly SST dataset is available from November 1981 to the present.

For the atmospheric data two sources were used: the National Centers for Environmental Prediction (NCEP)National Center for Atmospheric Research (NCAR) daily reanalysis (Kalnay et al. 1996; Kistler et al. 2001), available from 1948 to the present, and the 40-yr European Centre for Medium-Range Weather Forecasts (ECMWF) 
(a) Phases 2+3 - JFM

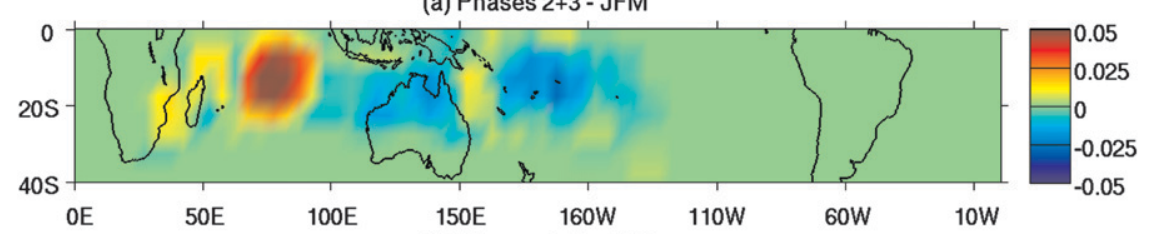

(b) Phases 4+5 - JFM

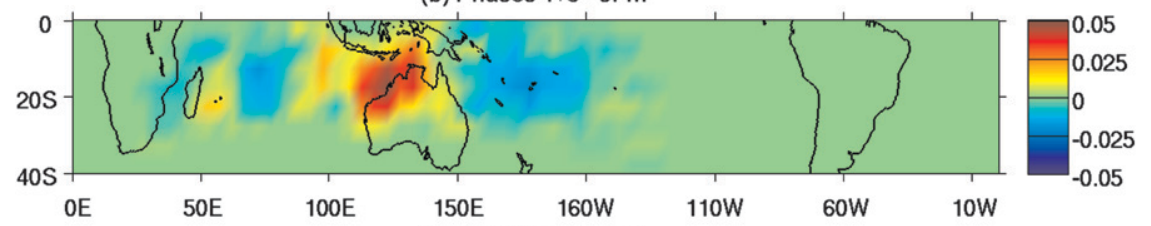

(c) Phases 6+7 - JFM

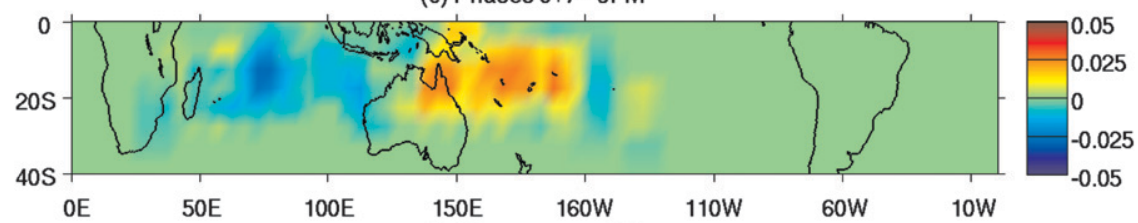

(d) Phases 8+1 - JFM

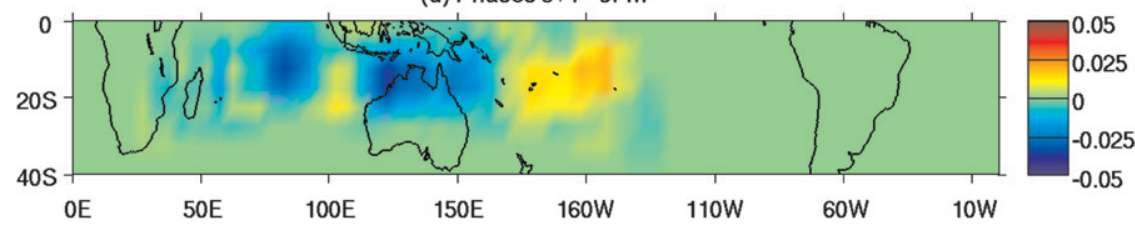

FIG. 3. First position density anomalies for JFM in the period 1982-2007 for MJO phases

(a) 2 and 3 (Indian Ocean), (b) 4 and 5 (Maritime Continent), (c) 6 and 7 (western Pacific),

(d) 8 and 1 (Western Hemisphere and Africa).

Re-Analysis (ERA-40) daily data (Uppala et al. 2005), available from mid-1957 to mid-2002.

Because both the SST data and the reanalysis data are necessary in our analysis, we used the common period available between the datasets (i.e., in the case of the NCEP-NCAR reanalysis November 1981 to December 2007, and for the ERA-40 reanalysis, November 1981 to July 2002). The climatological fields are defined for years when data for all months are available so that the climatology is based on an equal number of years for all months (i.e., 1982-2007 for NCEP-NCAR reanalysis and 1982-2001 for ERA-40 reanalysis).

The TC data are from the best-track datasets from the National Hurricane Center (NHC; Atlantic and eastern North Pacific; data available online at http://www.nhc. noaa.gov) and the Joint Typhoon Warning Center (JTWC; western North Pacific and North Indian Oceans and Southern Hemisphere; data available online at http://metocph.nmci.navy.mil/jtwc/best_tracks/). The central North Pacific TC data is based on the TCs that form in that region present in either the $\mathrm{NHC}$ or the JTWC datasets.

The daily outgoing longwave radiation (OLR) dataset from Liebmann and Smith (1996) available from 1974 to the present was also used.
The MJO is defined using the index of Wheeler and Hendon (2004) (covering 1974 to the present). The MJO phases are defined using the algorithm of Wheeler and Hendon (2004), and as a result our phases are identical to theirs for the period covered by their study.

\section{Genesis potential index}

We use the genesis potential index developed by Emanuel and Nolan (2004) and discussed in detail in Camargo et al. (2007a) and also used in Camargo et al. (2007b) and Nolan et al. (2007). The genesis potential index is defined as

$\mathrm{GP}=\left|10^{5} \eta\right|^{3 / 2}\left(\frac{\mathcal{H}}{50}\right)^{3}\left(\frac{\mathrm{PI}}{70}\right)^{3}\left(1+0.1 V_{\text {shear }}\right)^{-2}$

where $\eta$ is the absolute vorticity at $850 \mathrm{hPa}$ in $\mathrm{s}^{-1}, \mathcal{H}$ is the relative humidity at $600 \mathrm{hPa}$ in percent, PI is the potential intensity in $\mathrm{m} \mathrm{s}^{-1}$, and $V_{\text {shear }}$ is the magnitude of the vertical wind shear between 850 and $200 \mathrm{hPa}$ in $\mathrm{m} \mathrm{s}^{-1}$. As defined, GP is a positive-only quantity.

As shown in Camargo et al. (2007a), the GP climatology has local maxima in each of the regions with TC development globally. The annual cycle of the GP for each hemisphere and ocean basin also agrees well with 
(a) Phases 2+3 - ASO

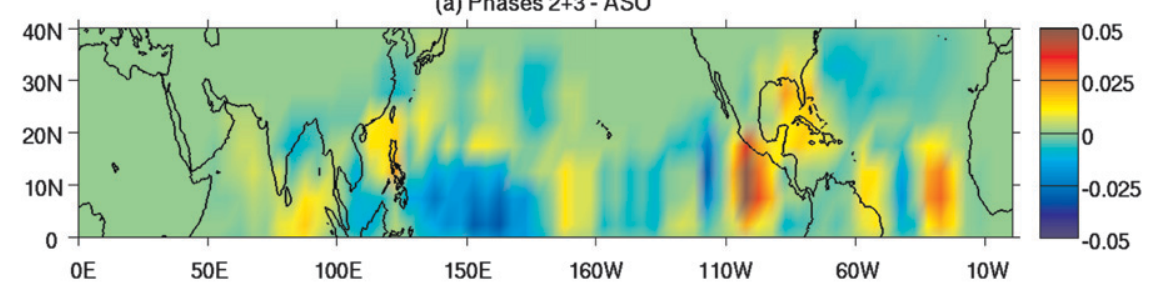

(b) Phases 4+5 - ASO

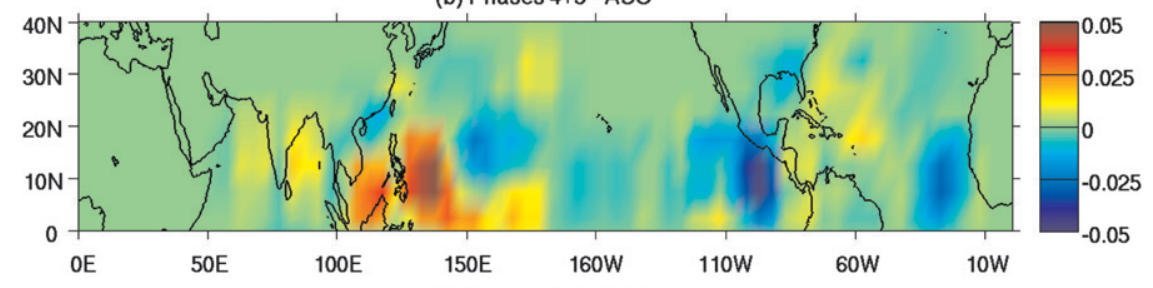

(c) Phases 6+7 - ASO

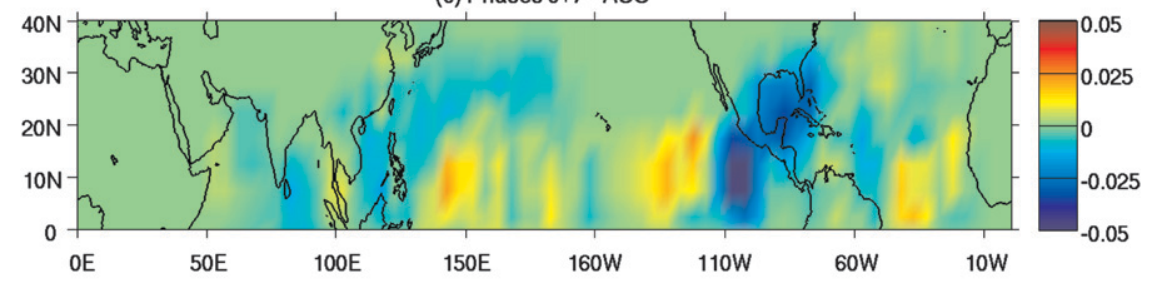

(d) Phases 8+1 - ASO

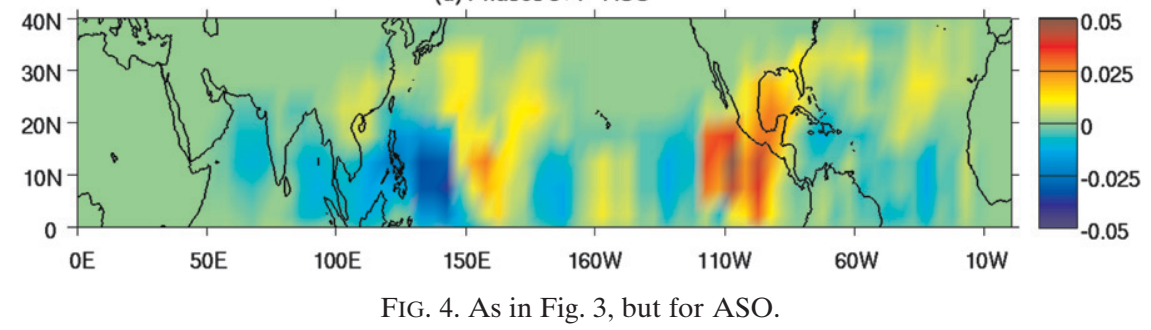

the annual cycle of observed genesis frequency in each region. It was also shown in Camargo et al. (2007a) that the anomaly composites of the GP for warm and cold El Niño-Southern Oscillation (ENSO) phases qualitatively replicate the observed ENSO-related interannual variations of the observed frequency and genesis location in several different basins.

In Camargo et al. (2007a), the GP was calculated using monthly mean atmospheric data from the NCEP-NCAR reanalysis and monthly mean SST data from the Reynolds dataset. Here, to resolve the MJO, we use daily atmospheric data from both the NCEP-NCAR and ECMWF reanalyses in conjunction with weekly SST data.

As a first step, we calculate the daily potential intensity (PI; Emanuel 1988, 1995; Bister and Emanuel 1998, 2002a,b). The algorithm is that of Bister and Emanuel (2002a,b), which includes dissipative heating. For this calculation we use weekly sea surface temperature, daily sea level pressure, and vertical profiles of atmospheric temperature and humidity. To further ensure that the GP composites we ultimately examine contain only in- traseasonal fluctuations, we apply a 7-day running mean time filter to all the atmospheric fields that enter the GP. Using these filtered fields, the daily GP is calculated.

From the resulting daily GP data, a daily GP climatology is constructed for the periods 1982-2007 (NCEPNCAR reanalysis) and 1982-2001 (ERA-40 reanalysis). The daily climatology is also smoothed with the same 7-day filter. Anomalous daily GP fields are then obtained by subtracting the daily climatological GP from the total GP daily fields for each year.

The GP MJO composites are then obtained by constructing means of the anomalous GP daily fields over each MJO phase, as defined by the Wheeler and Hendon (2004) index.

We examined several different variations on this compositing method. We considered the MJO cycle for both four phases and eight, and included either all data or only data from strong MJO events. The results are qualitatively insensitive to these variations. We present only results using the four MJO groups and including all data. 
(a) Phases 2+3 - JFM

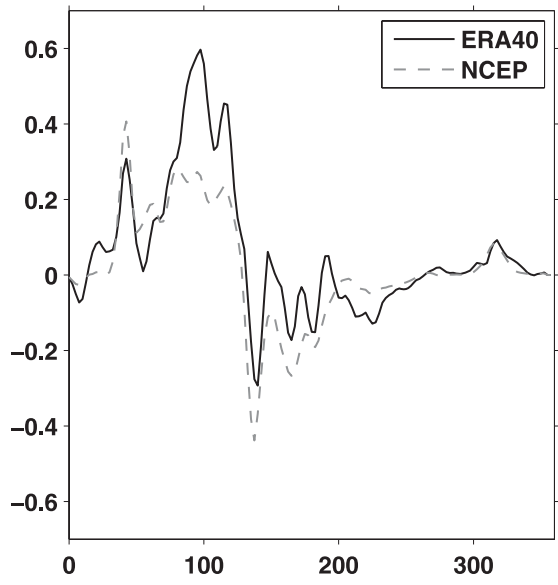

(c) Phases 6+7 - JFM

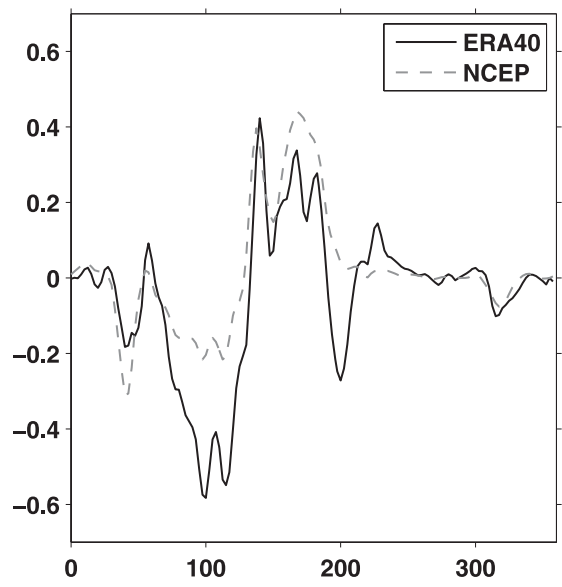

(b) Phases 4+5 - JFM

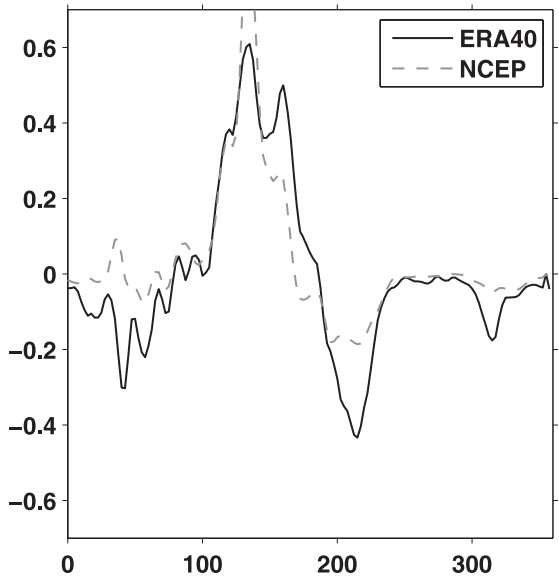

(d) Phases 8+1 - JFM

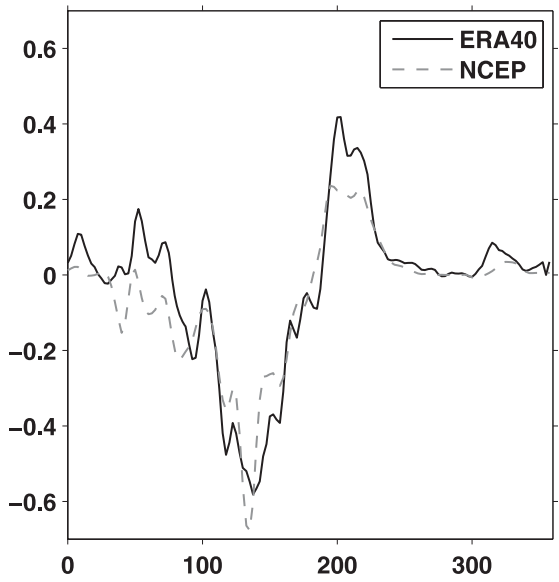

FIG. 5. Meridionally averaged $\left(30^{\circ} \mathrm{S}-0^{\circ}\right)$ GP anomaly composites for JFM in different MJO phases for the ERA-40 and NCEP-NCAR reanalysis data.

\section{Composites of genesis potential for the MJO phases}

\section{a. NCEP-NCAR reanalysis composites}

In Fig. 1 the MJO GP composites for the Southern Hemisphere's peak TC season, January-March (JFM), are shown. Each panel represents an average over two consecutive phases of the Wheeler-Hendon MJO index, starting from phases 2 and 3 when the convective envelope of the $\mathrm{MJO}$ is located over the Indian Ocean. As the convection of the MJO propagates eastward, indicated by negative OLR anomalies, so do the regions of positive GP anomalies. Both the regions of positive and negative GP anomalies show large coherent signals on the scale of the MJO, mostly overlapping the regions of negative and positive OLR anomalies, respectively. Similarly, in the case of the Northern Hemisphere summer [August-October (ASO)], shown in Fig. 2, there are coherent large-scale signals in the GP anomalies that match well the scale and eastward propagation of the
MJO. In phases 6 and 7, when the enhanced convective phase of the MJO lies in the western Pacific, there is a tendency for the GP anomalies to maximize poleward of the OLR anomalies in both hemispheres and seasons.

These two sets of composites were produced with no amplitude threshold on the MJO index, so all days of data are contained within them. As mentioned above, the results remain qualitatively the same when an MJO amplitude threshold is imposed. It is interesting to note that in the GP composites the MJO modulation over the Gulf of Mexico is as large as the modulation over the Indo-Pacific region.

\section{b. Observations of TC genesis}

Let us now compare the GP composites with the observed TC genesis in the different MJO phases. Using the best-track datasets for all TCs that reached tropical storm intensity or higher, we constructed climatological first-position density fields for JFM and ASO. The 
(a) JFM

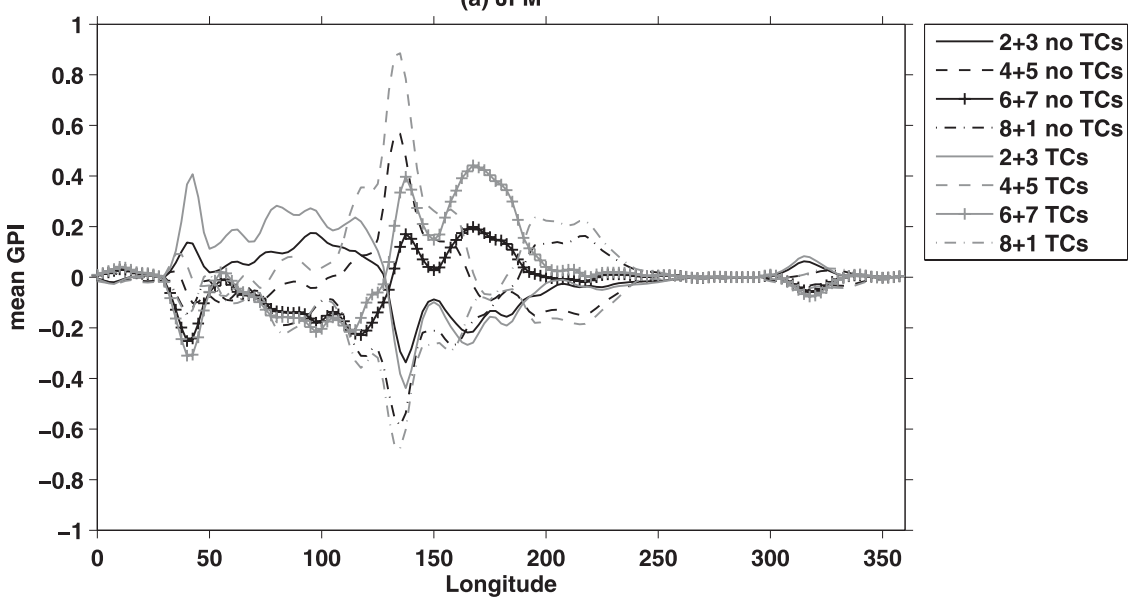

(b) ASO

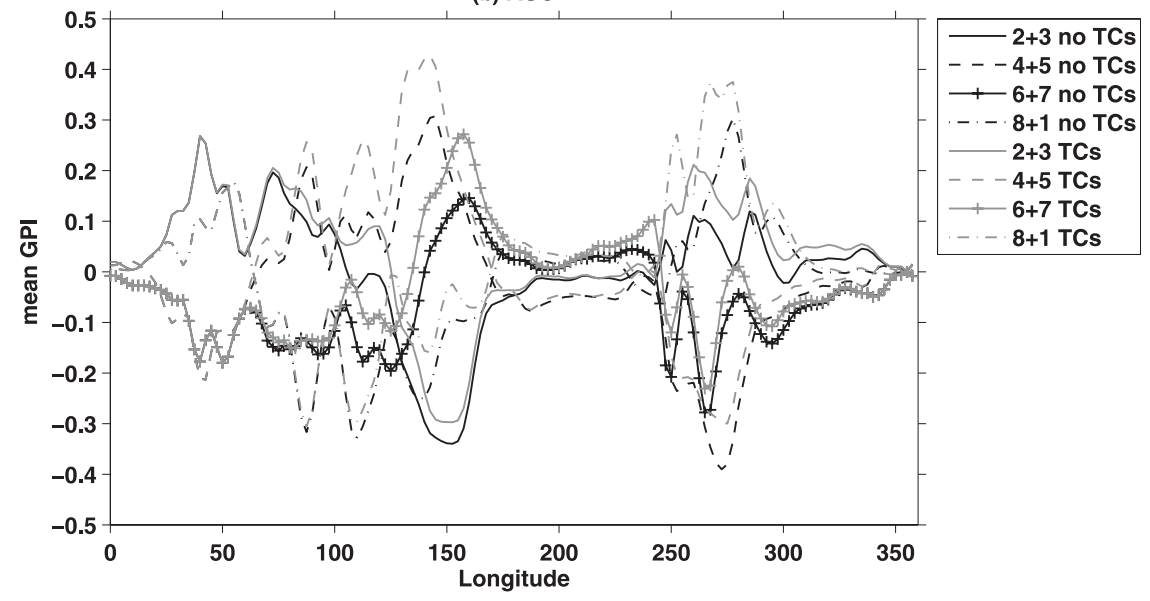

FIG. 6. Meridionally averaged GP anomaly composites for (a) JFM $\left(30^{\circ} \mathrm{S}-0^{\circ}\right)$ and (b) ASO $\left(0^{\circ}-30^{\circ} \mathrm{N}\right)$ in different MJO phases for the NCEP-NCAR reanalysis data with (gray) and without TCs (black).

resulting fields are noisy, so we smoothed these fields spatially. The spatial average was calculated by averaging nine grid points: the value of the grid point in consideration and the values of its eight nearest neighbors. To obtain the equivalent of the GP composites, we then constructed first position density fields for each of the MJO phases and smoothed these. Finally, from the first position density for each MJO phase, the corresponding seasonal climatology was subtracted. The resulting first position anomaly patterns are shown in Figs. 3 and 4 .

The modulation of the TC genesis frequency by the MJO is apparent in both JFM and ASO, although it is much noisier in the latter, presumably because of the greater amplitude of the MJO events during JFM. These TC genesis frequency composites well match the GP anomaly composites presented in Figs. 1 and 2, although the sometimes strong meridional gradients in the GP anomalies are not replicated in the first position com- posites because of the spatial smoothing of the latter. That this qualitative match between the TC first position fields is better with the GP than with the OLR shows the importance of more than just convection for modulating TC genesis, and the possible utility of the GP index for understanding the modulation.

\section{c. ERA-40 reanalysis composites}

To be sure that our results are independent of the reanalysis product used, we also constructed GP composites with the ERA-40 reanalysis data. The results for ERA-40 for JFM are shown in Fig. 5 with the corresponding NCEP reanalysis results for comparison, each meridionally averaged between $30^{\circ} \mathrm{S}$ and the equator. Although ERA-40 uses a slightly shorter time period, the patterns are very similar to those in the NCEP data. The same occurs in the Northern Hemisphere summer composites (not shown). From now on, we will just show 
(a) Potential Intensity - Phases 2+3 - JFM

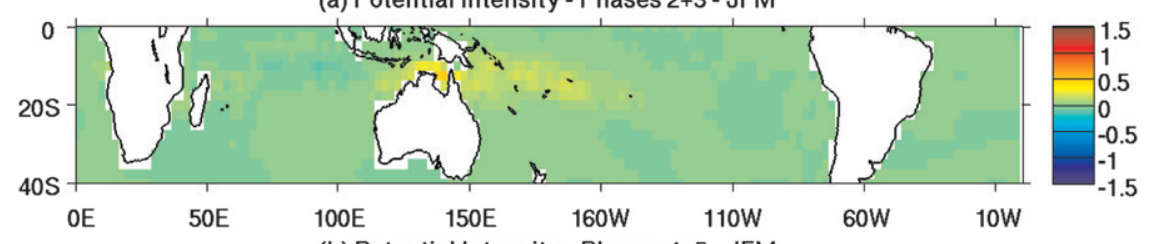

(b) Potential Intensity - Phases 4+5 - JFM

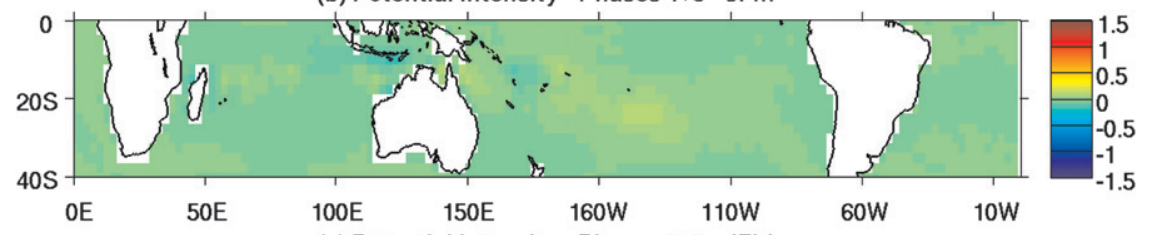

(c) Potential Intensity - Phases 6+7 - JFM

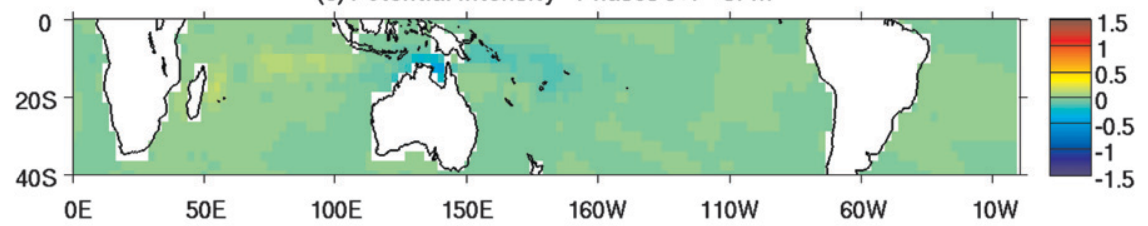

(d) Potential Intensity - Phases 8+1 - JFM

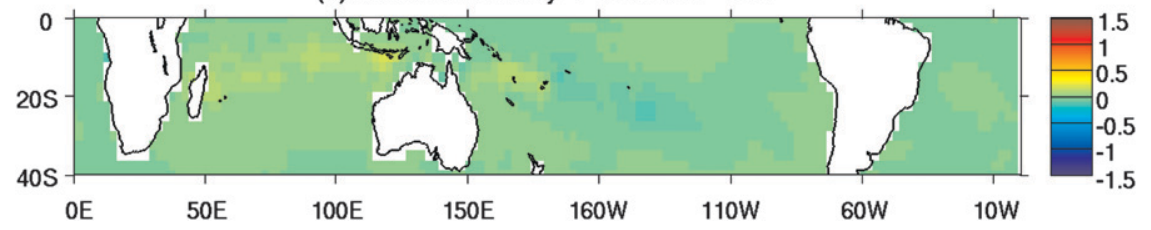

FIG. 7. GP composites for different MJO phases in JFM and without TCs for varying potential intensity (NCEP-NCAR reanalysis data). MJO phases are as in Fig. 1.

figures using the NCEP-NCAR reanalysis data, as the results using ERA-40 reanalysis data are very similar.

One difference between the ERA-40 and NCEPNCAR GP composites is that the ERA-40 GP composite values (climatology and anomalies) are substantially larger. The areal mean of the climatology in JFM (ASO) is 2.5 (3.4) times greater than the mean for the NCEP. Similarly, the mean of the absolute values of the anomaly composites averaged over the four MJO phases in JFM (ASO) is $27 \%$ (58\%) larger for the ERA-40 reanalysis than the NCEP-NCAR reanalysis. The differences between the NCEP-NCAR and ERA-40 reanalysis GP composites are due to differences in the relative humidity field that are amplified in the GP composites by the cubic exponent in (1) (not shown).

\section{Excluding the influence of TCs from the GP}

In this section we explore to what extent the TCs themselves are influencing the GP composites. Both reanalyses do include some representation of TCs, though presumably with a reduction in intensity and increase in horizontal scale due to the low resolution of the reanalysis.

To address this issue, we produced GP composites from which the effect of the TCs is excluded. Using the
NHC and the JTWC best-track datasets, we created a global best-track dataset for the period of the MJO composites. For each day in which one or more TCs is present in the global best-track dataset, we replace the GP field by its climatological value in a $12.5^{\circ} \times 12.5^{\circ}$ square centered on each TC center. This conservative (and admittedly crude) procedure ensures that the GP anomaly at and near the location of each TC is zero. The percentage of the total data removed in the $40^{\circ} \mathrm{S}$ to $40^{\circ} \mathrm{N}$ latitude band is small: $1.15 \%$ and $1.81 \%$ for JFM and ASO, respectively. Other methods have been used to assess the contribution of TCs to the climate (e.g., Hsu et al. 2008).

The resulting meridionally averaged GP composites are shown in Fig. 6 for the NCEP-NCAR reanalysis. When TCs are excluded from the composites, the GP anomalies are weaker, but the difference is not large. The same occurs for all cases examined: ASO as well as JFM, ERA-40 as well as the NCEP-NCAR reanalyses, and regardless of whether the MJO composites are four or eight phases and include all events or only the strong ones. Not only the amplitude but also the structure and propagation of the GP composite anomalies are very similar whether TCs are included or not. Thus, the MJO signals seen in the previous section are not artifacts 
(a) Relative Humidity - Phases 2+3 - JFM

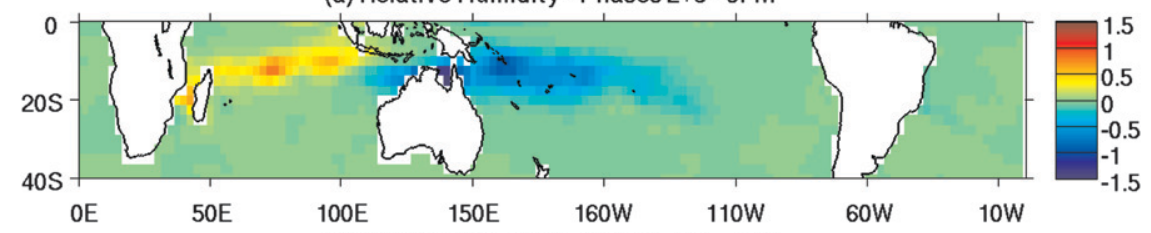

(b) Relative Humidity - Phases 4+5 - JFM

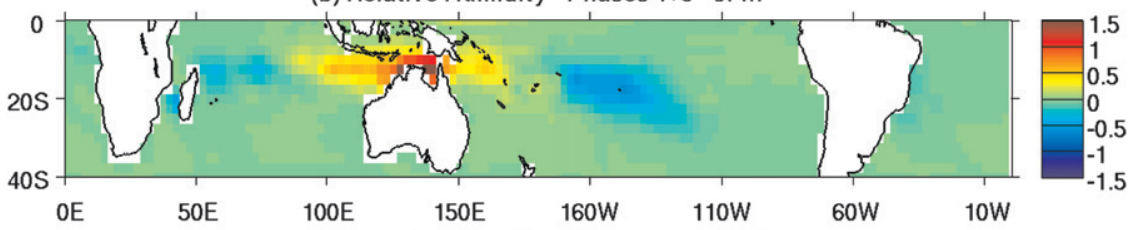

(c) Relative Humidity - Phases 6+7 - JFM

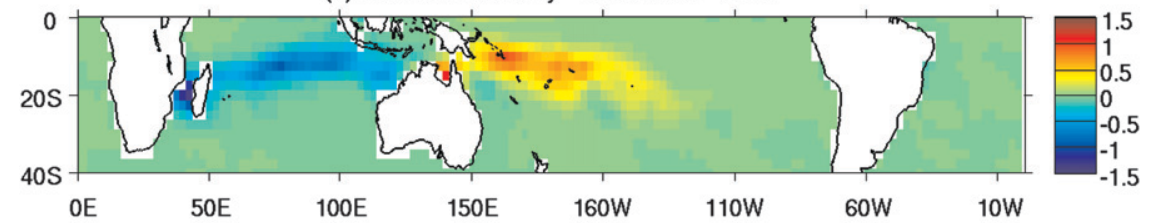

(d) Relative Humidity - Phases 8+1 - JFM

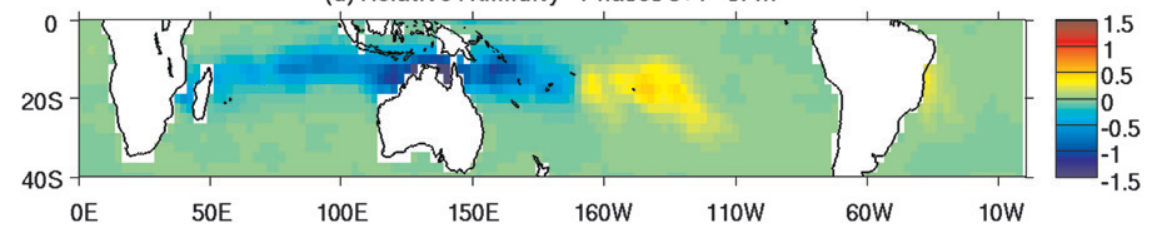

FIG. 8. As in Fig. 7, but for varying relative humidity.

ascribable to the presence of TCs in the datasets. Nonetheless, for quantitative purposes it may be desirable to exclude TCs when using the GP as an indicator of the likelihood of genesis (e.g., in forecasting). We also exclude them in our analysis below of the relative roles of the individual variables that enter the GP, but not for our calculations in section 7 .

\section{Diagnosing the influence of the individual GP variables}

In this section we assess the individual importance of each of the four variables that comprise the GP (lowlevel absolute vorticity, vertical wind shear, potential intensity, and midlevel relative humidity) in determining the MJO anomalies. To do that, we recalculate the GP using the climatological values (1982-2007) of three out of the four variables, but using the unmodified varying daily values of the fourth variable. This procedure is then repeated for the other three variables. We then recalculate the MJO composites in all four cases. This is the same procedure we used to examine the ENSO GP anomalies in Camargo et al. (2007a). As we discussed in that study, the GP index is nonlinear, so the total anomaly need not be equal to the sum of the four fields described here. However, in practice the nonlinearities are small because the sum of the four individual variables composites is very similar to that of the total anomalies. Therefore, this method provides useful quantitative estimates of the relative importance of the different factors in the MJO GP anomalies, and thus (given the results of the preceding sections) in the MJO-induced anomalies in TC genesis frequency.

The results of this analysis are for the most part qualitatively insensitive to variations in the reanalysis product used, the number of MJO phases, the inclusion or exclusion of TCs, and the season. Therefore, we only show graphically the results of one set of calculations, obtained using the NCEP-NCAR reanalysis for JFM and excluding the influence of TCs as described above. Figures 7, 8, 9, and 10 show the composites when only the potential intensity, the relative humidity, the vorticity, or the vertical shear varies, respectively, while the other three variables are given climatological values. By comparing these composites among themselves and also with the composites obtained when all factors are varying, it is apparent that the weights that the different factors contribute to the GP composites are different. The factor that contributes most to the GP anomalies is the relative humidity. The vertical shear and the absolute vorticity also contribute, but with weaker anomalies than the relative humidity. Of the two, vertical shear 
(a) Vorticity - Phases 2+3 - JFM

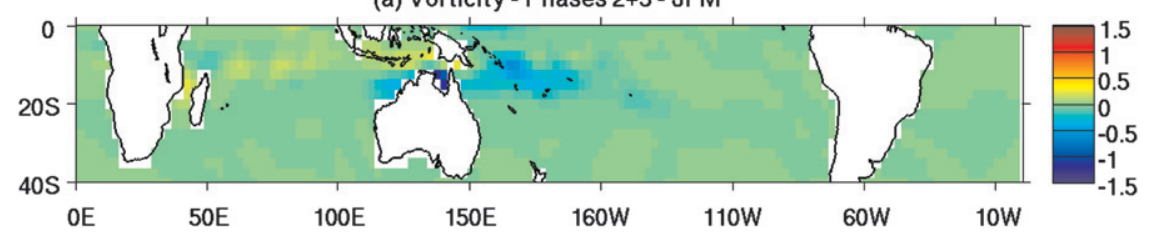

(b) Vorticity - Phases 4+5 - JFM
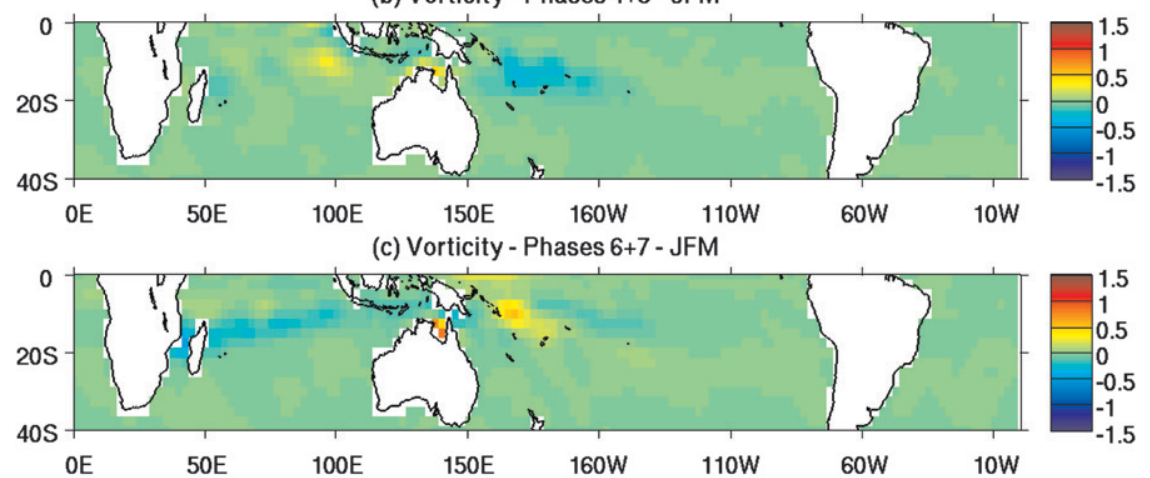

(d) Vorticity - Phases 8+1 - JFM

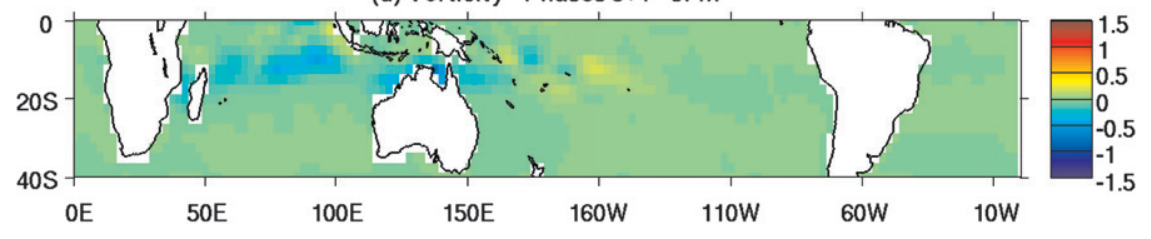

FIG. 9. As in Fig. 7, but for varying vorticity.

tends to have a stronger signal than vorticity, but shear tends to vary out of phase with the GP in some regions, indicating that it contributes negatively to the MJOinduced GP anomalies in those regions. Low-level absolute vorticity is somewhat noisy, but appears to contribute positively to the GP anomalies on the whole. In the potential intensity composites the anomalies are very weak.

When Camargo et al. (2007a) did a similar analysis for ENSO composites, it was found that the relative importance of the different factors in the GP was dependent on the region considered. In the case of the MJO composites, shown here (Figs. 7-10), the relative importance of the different factors is much more consistent from one region to the next.

A more quantitative measure of the contribution of each of the variables to the total composite is given in Table 1. In this table, the regression coefficients for the full composites and the individual variable composites are calculated for the different MJO phases for ASO and JFM for both the NCEP and the ERA-40 reanalysis. In each case, the spatial correlation was calculated only for the hemisphere in which the TC season was occurring (Northern Hemisphere for ASO, Southern Hemisphere for JFM). These regressions clearly show that the relative humidity is the most important factor contrib- uting to the MJO modulation of TC genesis frequency. The vorticity regression coefficients have consistently the second largest values, pointing to the secondary role of that variable. Only in a few cases do the regression coefficients of the vertical shear have values of the same magnitudes as the vorticity. For the most part, the same hierarchy among the regression coefficients is consistent between the two reanalyses. The only exception is that in ASO, in the ERA-40, the regression coefficients for vorticity are, on average over the four phases, nearly as large as those for relative humidity.

To assess the degree of nonlinearity in the GP, we calculated the sum of the four composites shown in Figs. 7-10 and compared it to the total GP composite (Fig. 11). The two have very similar patterns and amplitude, indicating that the nonlinearity is weak and thus the effectively linear analysis we have done in this section is valid.

This analysis points to a leading role of the relative humidity in the MJO modulation of TC genesis frequency, with a secondary role for the vorticity and a very weak influence of vertical shear. This differs from results from previous studies (Maloney and Hartmann 2000a,b; Hall et al. 2001; Bessafi and Wheeler 2006) that pointed to the dynamical factors as being most relevant for the MJO modulation of TCs. 
(a) Vertical Shear - Phases 2+3 - JFM

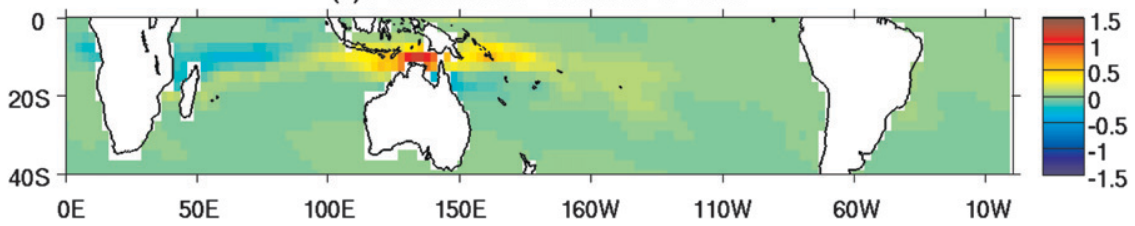

(b) Vertical Shear - Phases 4+5 - JFM

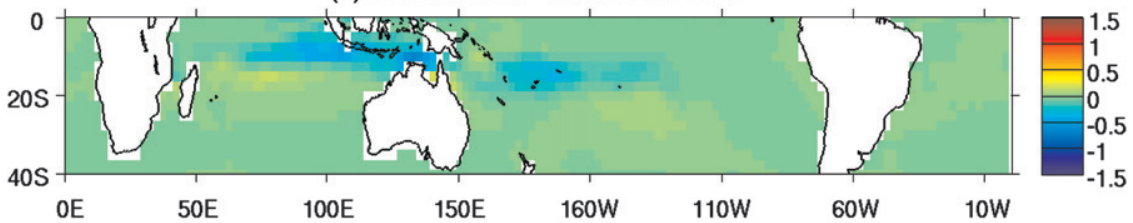

(c) Vertical Shear - Phases 6+7 - JFM

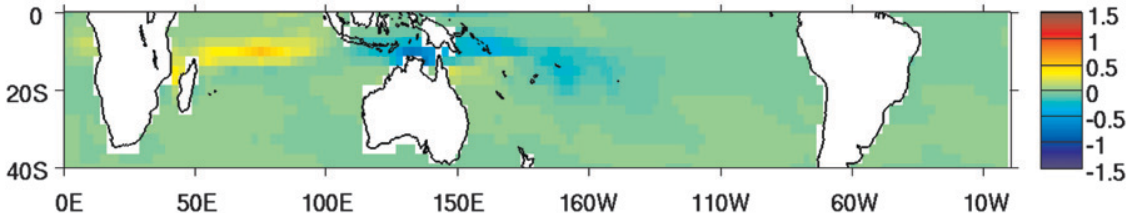

(d) Vertical Shear - Phases 8+1 - JFM

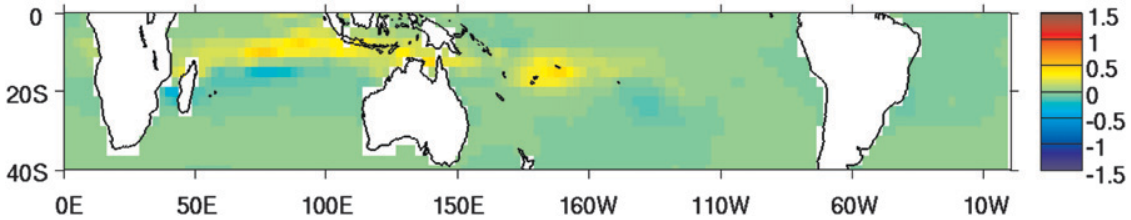

FIG. 10. As in Fig. 7, but for varying vertical shear.

\section{Quantification of the GP-TC relationship}

In sections 4 and 5 we have shown a relatively close qualitative match in spatiotemporal structure between the MJO fluctuations in the GP and the observed fluctuations in TC genesis frequency, with and without the influence of the TCs included in the GP. Now we wish to test how well the GP can quantitatively reproduce or predict the magnitude of the observed MJO fluctuations in TC genesis frequency. We do this by first regressing the climatological variations (from basin to basin and month to month) in the GP with the climatological variations in TC genesis frequency. This is the relationship originally used to derive the GP. We then compare this regression relationship with that obtained between the MJO-associated anomalies in GP and TC genesis frequency.

To do this, we first calculated the climatological monthly GP index for the period 1981-2007. We then calculated the integral of the GP index in each basin over all points at which the climatological value of the GP is larger than a specific threshold. This threshold was chosen to be 1.2 units, but the results are insensitive to its precise value. Finally, the resulting integrated monthly GP per basin was normalized by the number of days in the month considered. We then counted the number of
TCs that reached at least tropical storm strength that had formed in each region per month and constructed a climatology of the number of TCs per month per region, normalized by the number of days in each month.

TABLE 1. Regression coefficients $(\times 100)$ between the MJO composites of individual variables of GP index and the full field for the NCEP-NCAR reanalysis.

\begin{tabular}{|c|c|c|c|c|c|c|c|c|}
\hline \multicolumn{9}{|c|}{ ASO-Northern Hemisphere } \\
\hline \multirow[b]{2}{*}{ Phases } & \multicolumn{4}{|c|}{ NCEP-NCAR reanalysis } & \multicolumn{4}{|c|}{ ERA-40 reanalysis } \\
\hline & PI & RH & VR & $\mathrm{SH}$ & PI & $\mathrm{RH}$ & VR & SH \\
\hline $2+3$ & -1 & 67 & 25 & -3 & -1 & 49 & 22 & 2 \\
\hline $4+5$ & 1 & 59 & 24 & -3 & 2 & 47 & 42 & 0 \\
\hline $6+7$ & 1 & 49 & 14 & 17 & 2 & 35 & 24 & 22 \\
\hline $8+1$ & 2 & 52 & 29 & -1 & -1 & 37 & 37 & \\
\hline Mean & 1 & 57 & 23 & 3 & 1 & 42 & 31 & \\
\hline
\end{tabular}

JFM-Southern Hemisphere

\begin{tabular}{|c|c|c|c|c|c|c|c|c|}
\hline \multirow[b]{2}{*}{ Phases } & \multicolumn{4}{|c|}{ NCEP-NCAR reanalysis } & \multicolumn{4}{|c|}{ ERA-40 reanalysis } \\
\hline & PI & RH & VR & SH & PI & RH & VR & \\
\hline $2+3$ & -5 & 47 & 23 & 14 & -3 & 37 & 30 & \\
\hline $4+5$ & 0 & 67 & 13 & 4 & 3 & 60 & 17 & \\
\hline $6+7$ & -3 & 61 & 21 & 2 & -2 & 53 & 25 & \\
\hline $8+1$ & -5 & 74 & 19 & -4 & -4 & 58 & 19 & \\
\hline Mean & -3 & 62 & 19 & 4 & -2 & 52 & 23 & \\
\hline
\end{tabular}


(a) Sum - Phases 2+3 - JFM

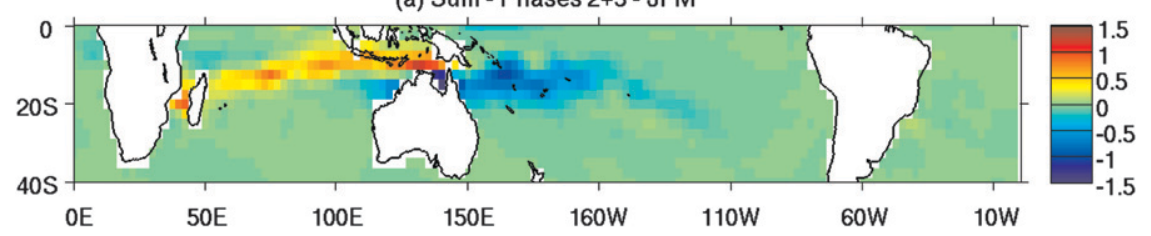

(b) Sum - Phases 4+5 - JFM

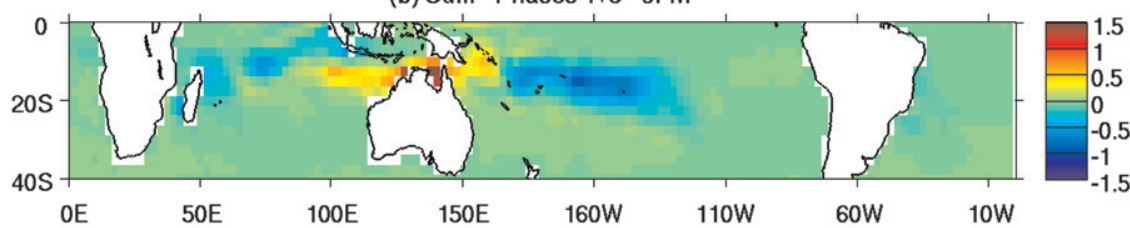

(c) Sum - Phases 6+7 - JFM

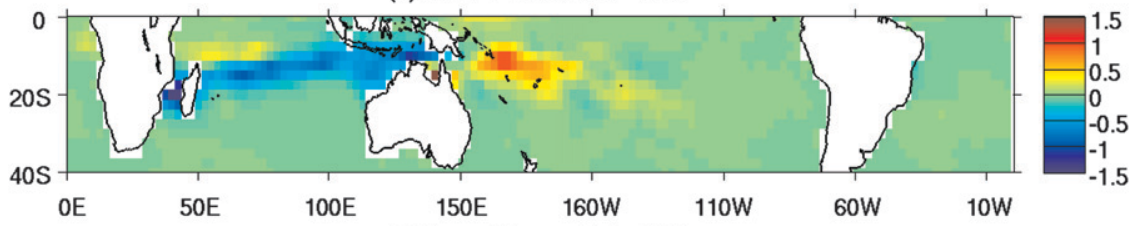

(d) Sum - Phases 8+1 - JFM

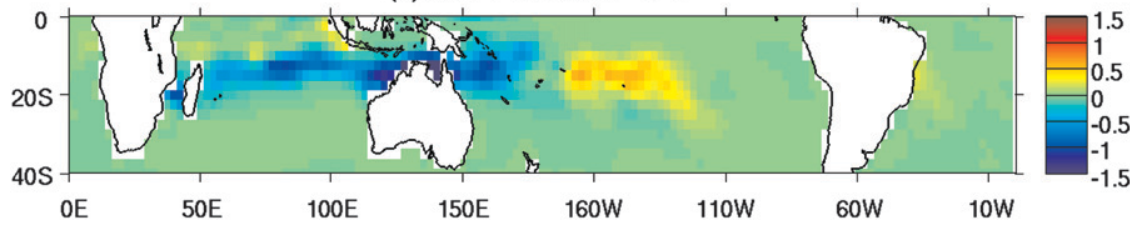

FIG. 11. Sum of the four GP composites of individual variables (Figs. 8-10) for different MJO phases in JFM and without TCs for the individual (NCEP-NCAR reanalysis data). MJO phases are as in Fig. 1.

The resulting relationship between the normalized integrated climatological GP index per month and normalized monthly number of TCs in the same regions is shown in Fig. 12a. Twelve points are shown for each region, one for each calendar month. There is a very clear relationship, with a highly significant correlation (0.93) between these two quantities. As expected, higher integrated values of normalized GP corresponded to higher values of TC genesis, with the highest values of GP occurring in the western North Pacific basin. This strong relationship is not surprising, since the GP index was designed by a fit to the climatological relationship between the large-scale environment and TC genesis. We present it to show the goodness of fit that is achieved (as measured by the correlation) and also to derive the regression slope for comparison to that obtained for the MJO anomalies. The regression slope for this case is $3.6 \times 10^{3}$, (confidence interval at the $5 \%$ significance level is $\left.3.3 \times 10^{3}-3.9 \times 10^{3}\right)$.

We then computed the anomalies of the normalized integrated GP index and number of TCs in each region and for the peak season in each hemisphere (ASO or JFM) for the different individual phases of the MJO. In this case, the integrated GP and number of TCs were normalized by the number of days in each MJO phase in the season considered. The resulting scatterplot is shown in Fig. 12b. The figure indicates that there is a relationship between the anomalies of GP index and NTC when the different MJO phases are considered, again with a highly significant correlation (0.78). However, the regression slope differs from what we had before (in this case, $1.7 \times 10^{3}$; the confidence interval is $1.2 \times 10^{3}-2.3 \times 10^{3}$ ). This means that only about half of the modulation of the TCs by the MJO is captured by the GP index. In the case of the ERA reanalysis an even larger portion of the variability may not be explained by the genesis index. Thus, although we were able to show a good qualitative match between the MJO-associated GP anomalies and TC genesis frequency in the previous sections, quantitatively there is a significant discrepancy in the magnitude of the fluctuations, at least if the regression slope from the climatology is taken as the basis for prediction.

There could be several reasons for the smaller regression slope and correlation coefficient obtained from the MJO anomalies compared to those obtained from the climatology. Part of the difference could result from imperfections in the index that derive either from inadequacies in the choice of predictors or errors in the 
(a)

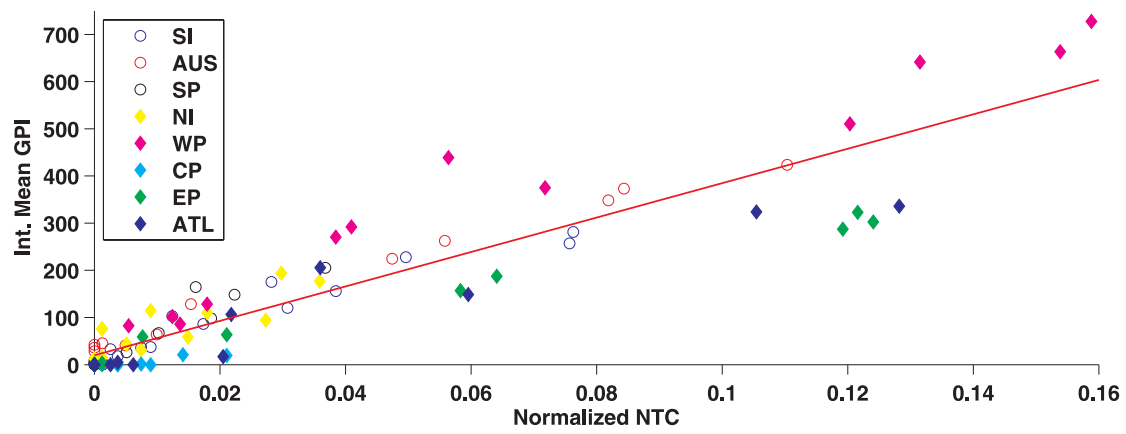

(b)

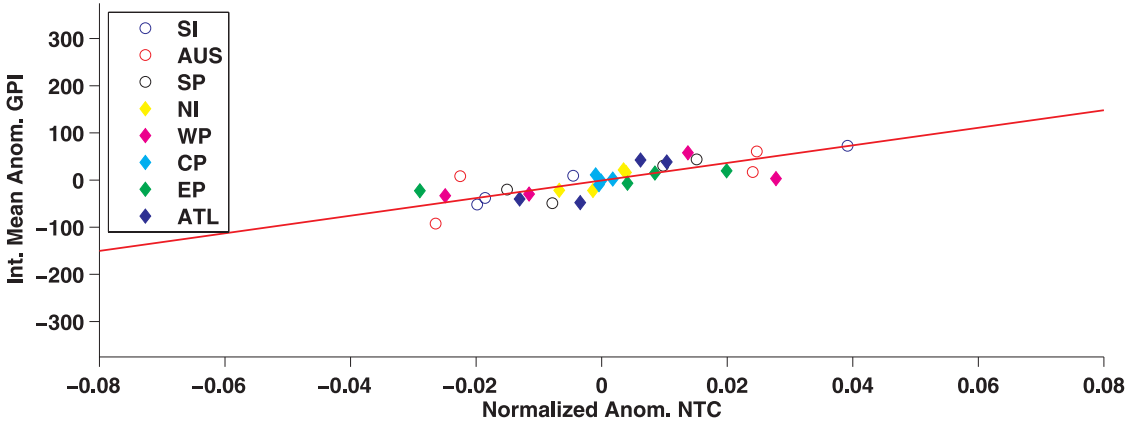

FIG. 12. Scatterplots of the integrated GP index (NCEP-NCAR reanalysis data) and normalized number of TCs in each ocean basin-South Indian (SI), Australia (AUS), South Pacific (SP), North Indian (NI), western North Pacific (WP), central North Pacific (CP), eastern North Pacific (EP), and Atlantic (ATL) - (a) for all months (b) anomalies per MJO phase in JFM (Southern Hemisphere basins) and ASO (Northern Hemisphere basins).

dependence of the index on those predictors (whose functional form comes from a fit to a finite sample of imperfect data). Perhaps equally or more likely is that on the intraseasonal time scale, variations in the occurrence or amplitude of synoptic-scale precursor disturbances to TC genesis become important. When evaluated from weekly or monthly data, the index is weakly or not at all influenced by the presence of such disturbances, but their presence or absence is certainly important to genesis instantaneously. It is reasonable to expect that this will be a more important limitation on the GP's utility for prediction on the shorter time scale under consideration, and thus that the GP will not be as successful in predicting the MJO-associated variance in genesis as it is in capturing the climatology (to which, again, it was tuned). Another possible reason could be that the reanalysis datasets are not capturing the amplitude of the MJO signal. Humidity in particular - an important variable in our analysis-is less constrained in the reanalyses to be close to observations than are temperature and wind. The humidity is more strongly determined by the numerical model used in the data assimilation process and thus more uncertain. The differences between the NCEP-NCAR and ERA-40 relative humidity fields make this evident.

\section{Conclusions}

We have examined the modulation of the global TC genesis by the MJO using a GP index. Our primary conclusions are as follows:

1) The GP captures the spatiotemporal structure of observed variations in TC genesis frequency induced by the MJO. Positive GP anomalies well match the regions of enhanced TC genesis frequency, which tend to be centered slightly poleward and a little westward of the center of the convective envelope of the MJO.

2) The primary contribution of the MJO to the modulation of TCs as implied by the GP index is its modulation of midlevel relative humidity. The second largest contribution comes from the low-level absolute vorticity, and only very minor contributions come from the vertical wind shear and potential intensity.

3) The quantitative relationship between the MJOassociated anomalies in the GP index and TC genesis frequency is different from, and weaker than, the comparable relationship obtained from the climatology. This may result either from flaws in the reanalyses, particularly the humidity fields, or in the 
definition of the index itself. Among other possibilities, it is possible that a lack of information about precursor disturbances, such as results when the index is computed from weekly data, may be a more important factor on intraseasonal time scales than it is for the climatology or interannual variability.

Acknowledgments. The ECMWF ERA-40 data used in this study were obtained from the ECMWF data server. SJC and AHS acknowledge support from NOAA Grant NA08OAR4320912. Much of this work was done while AHS was a sabbatical visitor at the Centre for Australian Weather and Climate Research at the Bureau of Meteorology office in Melbourne, Australia, and he thanks the scientists and administrative staff of that institution for their hospitality and support. We thank Kerry Emanuel and John Molinari for their insightful comments on this paper.

\section{REFERENCES}

Aiyyer, A. R., and J. Molinari, 2008: MJO and tropical cyclogenesis in the Gulf of Mexico and Eastern Pacific: Case study and idealized numerical modeling. J. Atmos. Sci., 65, 2691-2704.

Bessafi, M., and M. C. Wheeler, 2006: Modulation of South Indian Ocean tropical cyclones by the Madden-Julian oscillation and convectively coupled equatorial waves. Mon. Wea. Rev., 134, 638-656

Bister, M., and K. A. Emanuel, 1998: Dissipative heating and hurricane intensity. Meteor. Atmos. Phys., 52, 233-240.

$\ldots$, and - 2002a: Low frequency variability of tropical cyclone potential intensity. 1. Interannual to interdecadal variability. J. Geophys. Res., 107, 4801, doi:10.1029/2001JD000776.

$\longrightarrow$, and,$- 2002 \mathrm{~b}$ : Low frequency variability of tropical cyclone potential intensity. 2. Climatology for 1982-1995. J. Geophys. Res., 107, 4621, doi:10.1029/2001JD000780.

Camargo, S. J., K. A. Emanuel, and A. H. Sobel, 2007a: Use of a genesis potential index to diagnose ENSO effects on tropical cyclone genesis. J. Climate, 20, 4819-4834.

- A. H. Sobel, A. G. Barnston, and K. A. Emanuel, 2007b: Tropical cyclone genesis potential index in climate models. Tellus, 59A, 428-443.

—,$\ldots$, and P. J. Klotzbach, 2009: The influence of natural climate variability on tropical cyclones and seasonal forecasts of tropical cyclone activity. Global Perspectives on Tropical Cyclones. 2nd ed. World Scientific, in press.

Emanuel, K. A., 1988: The maximum intensity of hurricanes. J. Atmos. Sci., 45, 1143-1155.

- 1995: Sensitivity of tropical cyclones to surface exchange coefficients and a revised steady-state model incorporating eye dynamics. J. Atmos. Sci., 52, 3969-3976.

— climate. Preprints, 26th Conf. on Hurricanes and Tropical Meteorology, Miami, FL, Amer. Meteor. Soc., 240-241.

Hall, J. D., A. J. Matthews, and D. J. Karoli, 2001: The modulation of tropical cyclone activity in the Australian region by the Madden-Julian oscillation. Mon. Wea. Rev., 129, 2970-2982.
Ho, C.-H., J.-H. Kim, J.-H. Jeong, H.-S. Kim, and D. Chen, 2006: Variation of tropical cyclone activity in the South Indian Ocean: El Niño-Southern Oscillation and Madden-Julian oscillation effects. J. Geophys. Res., 111, D22101, doi:10.1029/ 2006JD007289.

Hsu, H. H., C. H. Hung, A. K. Lo, C. C. Wu, and C. W. Hung, 2008: Influence of tropical cyclones on the estimation of climate variability in the tropical western North Pacific. J. Climate, 21, 2960-2975.

Kalnay, E., and Coauthors, 1996: The NCEP/NCAR 40-Year Reanalysis Project. Bull. Amer. Meteor. Soc., 77, 437-441.

Kistler, R., and Coauthors, 2001: The NCEP-NCAR 50-Year Reanalysis: Monthly means CD-ROM and documentation. Bull. Amer. Meteor. Soc., 82, 247-267.

Leroy, A., and M. C. Wheeler, 2008: Statistical prediction of weekly tropical cyclone activity in the Southern Hemisphere. Mon. Wea. Rev., 136, 3637-3654.

Liebmann, B., and C. A. Smith, 1996: Description of a complete (interpolated) outgoing longwave radiation dataset. Bull. Amer. Meteor. Soc., 77, 1275-1277.

— , H. H. Hendon, and J. D. Glick, 1994: The relationship between tropical cyclones of the western Pacific and Indian Oceans and the Madden-Julian oscillation. J. Meteor. Soc. Japan, 72, 401-412.

Madden, R. A., and P. R. Julian, 1972: Description of global circulation cells in the tropics with a 40-50-day period. J. Atmos. Sci., 29, 1109-1123.

—, and —- 1994: Observations of the 40-50-day tropical oscillation-A review. Mon. Wea. Rev., 122, 814-837.

Maloney, E. D., and D. L. Hartmann, 2000a: Modulation of eastern North Pacific hurricanes by the Madden-Julian oscillation. J. Climate, 13, 1451-1460.

— and - 2000b: Modulation of hurricane activity in the Gulf of Mexico by the Madden-Julian oscillation. Science, 287, 2002-2004.

_ , and _ 2001: The Madden-Julian oscillation, barotropic dynamics, and North Pacific tropical cyclone formation. Part I: Observations. J. Atmos. Sci., 58, 2545-2558.

Molinari, J., D. Knight, M. Dickinson, D. Vollaro, and S. Skubis, 1997: Potential vorticity, easterly waves, and Eastern Pacific tropical cyclogenesis. Mon. Wea. Rev., 125, 2699-2708.

Nakazawa, T., 1988: Tropical super clusters within intraseasonal variations over the western Pacific. J. Meteor. Soc. Japan, 66, 823-839.

Nolan, D. S., E. D. Rappin, and K. A. Emanuel, 2007: Tropical cyclogenesis sensitivity to environmental parameters in radiative-convective equilibrium. Quart. J. Roy. Meteor. Soc., 133, 2085-2107.

Reynolds, R. W., N. A. Rayner, T. M. Smith, D. C. Stokes, and W. Wang, 2002: An improved in situ and satellite SST analysis for climate. J. Climate, 15, 1609-1625.

Uppala, S. M., and Coauthors, 2005: The ERA-40 Re-Analysis. Quart. J. Roy. Meteor. Soc., 131, 2961-3012, doi:10.1256/ qj.04.176.

Wang, B., and H. Rui, 1990: Synoptic climatology of transient tropical intraseasonal convection anomalies: 1975-1985. Meteor. Atmos. Phys., 44, 43-61.

Wheeler, M. C., and H. H. Hendon, 2004: An all-season real-time multivariate MJO index: Development of an index for monitoring and prediction. Mon. Wea. Rev., 132, 1917-1932.

Zhang, C., 2005: Madden-Julian oscillation. Rev. Geophys., 43, RG2003, doi:10.1029/2004RG000158. 